\title{
Pet rat harbouring Seoul hantavirus in Sweden, June 2013
}

Å Lundkvist (ake.lundkvist@smi.se)1,2,3, J Verner-Carlsson ${ }^{1,2}$, A Plyusnina $^{4}$, L Forslund 5 , R Feinstein ${ }^{5}$, A Plyusnin 4

1. Swedish Institute for Communicable Diseases, Solna, Sweden

2. Karolinska Institutet, Stockholm, Sweden

3. BMC, IMBIM, Uppsala University, Uppsala, Sweden

4. Haartman Institute, Helsinki, Finland

5. The National Veterinary Institute, Uppsala, Sweden

Citation style for this article:

Lundkvist A, Verner-Carlsson J, Plyusnina A, Forslund L, Feinstein R, Plyusnin A. Pet rat harbouring Seoul hantavirus in Sweden, June 2013. Euro Surveill. 2013;18(27):pii=20521. Available online: http://www.eurosurveillance.org/ViewArticle.aspx?Articleld=20521

We report the first detection of Seoul hantavirus (SEOV) in a pet rat in Sweden. SEOV-specific antibodies were detected in the pet rat blood by focus reduction neutralising test (FRNT), and SEOV RNA in lung tissue was confirmed by reverse transcription-nested polymerase chain reaction (RT-PCR) followed by sequencing. The discovery follows the recent reports of SEOV infected pet rats, as well as associated human cases of severe haemorrhagic fever with renal syndrome (HFRS), in England and Wales.

In June 2013, Seoul hantavirus (SEOV) was detected for the first time in a pet rat in Sweden. The rat had been imported to Sweden from England in 2011. During the winter 2012/13, the presence of SEOV, both in wildand in pet rats, as well as associated severe human cases of haemorrhagic fever with renal syndrome (HFRS), were reported in England and Wales [1,2]. In Sweden, this raised concerns among owners of pet rats imported from the United Kingdom (UK) that such animals may be infected. During late spring, three rat owners initially came forward to have their pet rats tested by the National Veterinary Institute (SVA), and among the three respective rats tested, one was found to be SEOV infected.

\section{Background}

Hantaviruses (family Bunyaviridae) are three-segmented, negative-stranded RNA viruses transmitted by rodents, insectivores and bats. Over 40 hantavirus species, or potential species, are currently known, and most of them are restrained to a single reservoir host species. Several hantaviruses are human pathogens (notably all those associated with rodents), causing up to 50,000 disease cases annually worldwide [3 and references therein].

The bank vole Myodes glareolus is the reservoir of Puumala hantavirus (PUUV), which causes nephropathia epidemica (NE), a milder form of HFRS that accounts for the majority of hantavirus-related disease incidence in Europe. Other European hantavirus pathogens causing HFRS, are Dobrava (DOBV) and Saaremaa (SAAV) viruses, carried respectively by mice of the species Apodemus flavicollis and A. agrarius [3-6]. These are the species listed by the International Committee on Taxonomy of Viruses, but the nomenclature of the European Apodemus-derived hantaviruses has been and still is, under debate and revision: in the literature DOBVvariants in A. flavicollis are also referred to as DOBV-Af, and variants in $A$. ponticus as DOBV-Ap. Some strains recovered from $A$. agrarius are described as a genotype DOBV-Aa [6].

As hantaviruses are strictly associated with their rodent, bat or insectivore hosts, the distribution of hantaviruses is limited to that of their respective host species. SEOV is an exceptional hantavirus in that it has a global distribution due to the worldwide dispersal of its carrier host, the rat of the species Rattus norvegicus, mainly through global trade. Although rats are unaffected by the virus, SEOV causes a more severe form of HFRS in humans (mortality approximately $2 \%$ ), and this has been observed mainly in Asia [6]. Outside of Asia, SEOV has been found, by molecular methods, in rats in the Americas [7] and in Europe (Belgium, France and the UK) [8-11]. During the winter 2012/13, human cases of severe HFRS caused by SEOV were reported in the UK and France $[1,2,11]$. In the UK, some of the SEOV cases were associated with pet rats [2]. This report describes the first finding of SEOV in a pet rat in Sweden.

\section{Virus investigation}

The sampling of the pet rats' blood and organs (e.g. lungs, kidneys, liver) was conducted at the SVA. Approximately $500 \mathrm{mg}$ of the rat lungs were cut to smaller pieces and vortexed with $1 \mathrm{ml}$ of PBS. The lung tissue samples were centrifuged for $1 \mathrm{~min}$ and the supernatant diluted 1:5 and mixed 1:1 with virus dilution resulting in a final concentration of 1:10 (corresponding, based on earlier comparisons of serum 
antibodies and antibodies extracted from rodent lung tissue in our laboratory, to a serum concentration of approximately 1:200) for the initial screening.

Focus reaction neutralisation test (FRNT), the gold standard for typing of hantavirus antibody responses, was performed as described earlier [12]. An $80 \%$ reduction of the number of foci, as compared to the virus control, was used as the criterion for virus neutralisation titres.

The initial screening clearly showed the presence of SEOV-specific neutralising antibodies in a lung tissue sample (number 1466) from one of the three rats investigated. When titrating the supernatant, the result was repeated with a complete neutralisation at the 1:10 dilution. The corresponding serum dilution of the sample from the lung is hard to define, but we estimate it to correspond to a serum dilution of at least 1:200.

$220 \mathrm{mg}$ of lung tissue from the FRNT-positive rat was homogenised with $2,5 \mathrm{ml}$ of Trizol (Life technologies) and RNA was extracted according to manufacturer's instructions.

Reverse transcription (RT)-nested polymerase chain reaction (PCR) was performed on the purified RNA of the pet rat as described before [10]. Partial sequence of the hantavirus L segment (nt 2,968 to 3,300) was targeted by the PCR. The obtained sequence was analysed by sequence alignment to other hantavirus sequences available from GenBank and by phylogenetic analysis. Multiple sequence alignment was conducted with the SeqApp 1.9 a169 programme. Phylogeny was inferred using the Phylogeny Inference Package (PHYLIP) programme [13]. Five-hundred bootstrap datasets were generated using the 'Seqboot' programme. Genetic distances were calculated using the 'Dnadist' programme under the maximum likelihood model for nucleotide substitutions and the resulted distant matrices were analysed with the neighbour joining (NJ) tree-fitting algorithm ('Neighbour' programme). The bootstrap support values were calculated with the 'Consense' programme.

The analyses showed that the sequence was indeed derived from a SEOV species and the newly detected strain was designated SEOV/Sweden/Rn1466/2013, or Sweden1466 for short. The Swedish strain was found most closely related to SEOV strains from Indonesia (1 substitution, sequence identity of $99.7 \%$ ) and Belgium (9 substitutions, sequence identity of $97.3 \%$ ). All nucleotide substitutions were silent, i.e. the deduced partial amino acid sequences of Swedish, Indonesian and Belgian strains were $100 \%$ identical. On the phylogenetic tree (Figure) these three strains formed SEOV genetic lineage number 7 which was clearly distinct from lineages formed by strains from the UK (Humber), South Korea (80-39) and China (L99, Z37, ZT10, ZT71). The strain from Sweden differed from the UK strain Humber by 23 point mutations, all silent.
The pet rat diagnosed with SEOV was a male which had been imported to Sweden for breeding purposes in 2011 and had a proven pedigree. It had come from England together with 19 other pet rats. All 20 pet rats had been grouped together for transport reasons, but had different backgrounds in the UK, and were separated when they were delivered to different families in Sweden. Because they had been in close contact with the infected rat, the 19 co-imported pet rats from England to Sweden were delivered to the SVA and are in the process of being tested, as they are suspect for SEOV infection.

\section{Control measures}

Transmission of hantaviruses to humans most frequently occurs through breathing of aerosols of viruscontaminated rodent excreta [6]. Large quantities of infectious virus are excreted in the urine, saliva and faeces of the infected rodents. Recent results on PUUV have shown; (i) that the secreted virus is surprisingly stable, and thereby infectious over long time-periods outside the rodent host [14], and (ii) the virus is secreted for several months, or even years, after the infection [15; data not shown].

The unique finding in this study of a strain of SEOV in a Swedish pet rat, rather than in wild rats, poses a challenge for infection control and will involve a multi-disciplinary panel including medical/science experts from e.g. the Swedish Institute for Communicable Diseases (SMI), the SVA, the National Board of Health and Welfare (SoS) and the Swedish Board of Agriculture. At this time, the owner of the SEOV-infected rat is being offered clinical follow-up and all the concerned pet handlers both in Sweden and the UK have been informed of the finding and offered advice. Human samples as well as more rats are in the process of being tested. Interim guidance on minimising the infection to the pet rat community has earlier been published in the UK (http://www.hpa.org.uk/Topics/InfectiousDiseases/ InfectionsAZ/Hantaviruses/) and in Sweden (www.sva. se), and will continue to be updated as the investigations progress. Recommendations for managements of any future finding of infection in a pet rat would be made on a case-by-case basis. Further studies are planned to collect evidence on the prevalence of this virus in the pet rat community, as well as in wild rats in selected geographical areas of Sweden (e.g. international harbours where rats originating from different geographical areas may be found), which will inform future risk assessment and the provision of appropriate public health guidance.

\section{Discussion and conclusions}

In December 2012, our colleagues in the UK reported the first discovery of SEOV in wild Rattus norvegicus that were associated to a severe case of HFRS in the UK [1]. In February 2013, pet rats as a source of SEOV, and also associated severe human disease, were reported from England and Wales [2]. 


\section{FIGURE}

Phylogenetic analysis of a sequence derived from a pet-rat suspected of hantavirus infection, Sweden, June 2013

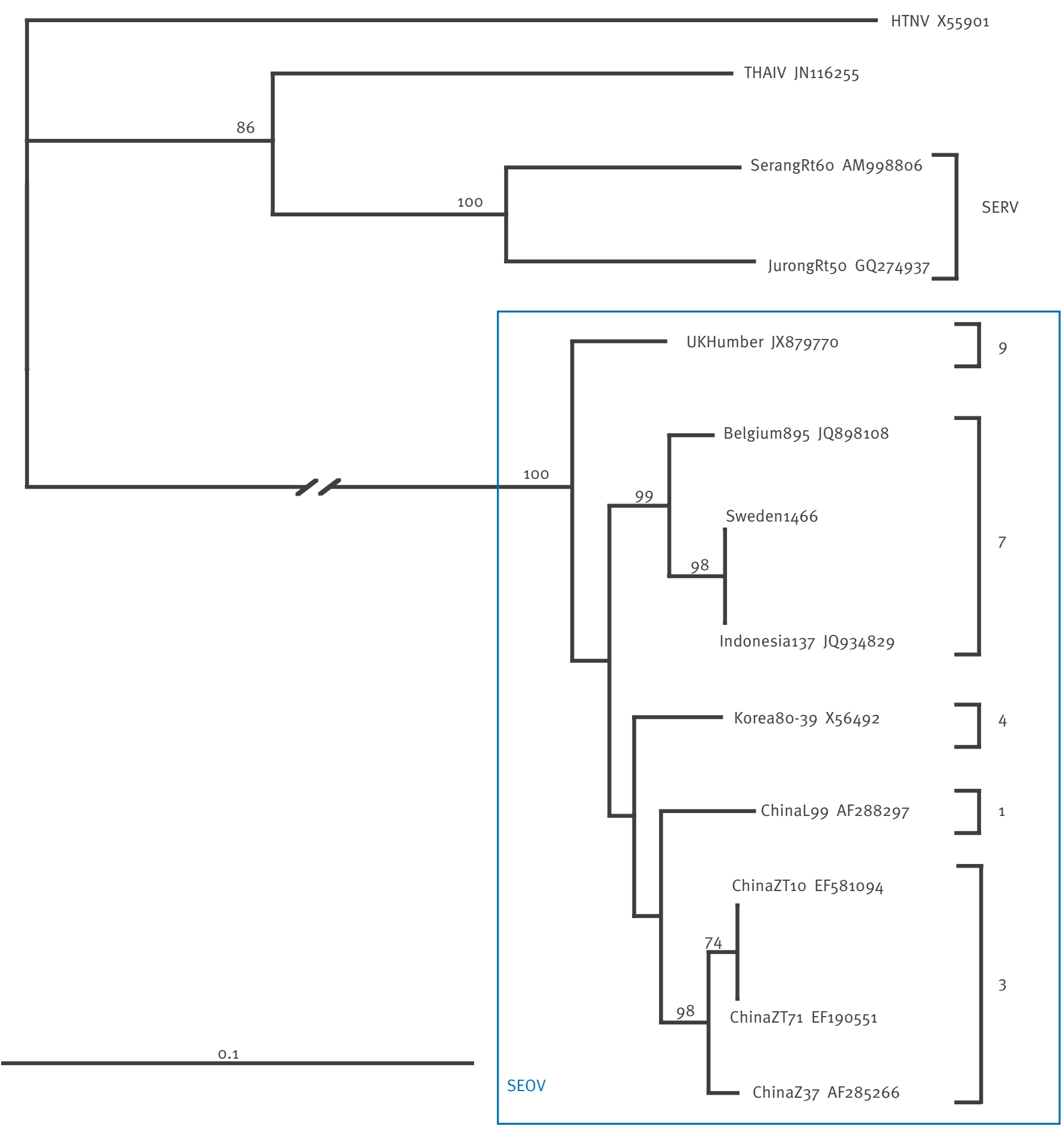

HTNV: Hantaan virus, strain 76-118; SEOV: Seoul virus; THAIV: Thailand virus, strain ThaiR5370; SERV: Serang virus.

The phylogenetic tree is based on partial L segment sequences (nt 2,968 to 3,300) of hantaviruses. GenBank accession numbers of the sequences figure on the tree. The HTNV sequence was used as an outgroup. Bootstrap support values greater than $70 \%$ are shown at the nodes. SerangRt60 and JurongRt50 sequences were used as representative strains of SERV. Belgium895, Indonesia137, UKHumber, Korea80-39, ChinaL99, ChinaZ37, ChinaZT71, and ChinaZT10 sequences were strains of SEOV. For sequences or clusters of sequences belonging to the SEOV, the corresponding lineage number is indicated to the side of the phylogenetic tree. 
We now report the first SEOV variant ever found in Sweden, similar, but genetically distinct from the available SEOV strains reported to date. At this moment, we cannot tell if the rat had been infected in the UK, or later in Sweden. Further investigations will reveal the relationship of various SEOV strains in Europe, and how they are associated to pet rat and wild rat populations. So far, representatives of two genetic lineages of SEOV have been found in Europe: lineage number 9 (including strain Humber from the UK) and lineage number 7 (including the strain from Sweden reported here as well as strains from Belgium and most likely also strains from France, since Belgian and French strains are very close in their S and M segment sequences [10]).

Currently, the prevalence of SEOV in the Swedish pet rat community is unknown, but further investigations have been planned. Should overall findings indicate that further health protection advice is necessary, SMI and SVA will work with the relevant partners to provide this. At this time there is no evidence of human (HFRS type) disease associated with pet rats in Sweden.

\section{Acknowledgements}

The authors thank the rat owners for their cooperation. This study was partially funded by EU grant FP7-261504 EDENext and is catalogued by the EDENext Steering Committee as EDENext155 (http://www.edenext.eu). The authors thank Lena Renström for valuable comments.

\section{Conflict of interest}

None declared.

\section{Authors' contributions}

Åke Lundkvist - Planning and responsible for the study, writing of the manuscript. Jenny Verner-Carlsson - Performed the serological analyses. Angelina Plyusnina - Performed the molecular analyses. Linda Forslund - Performed the animal sampling. Ricardo Feinstein - performed the animal sampling. Alexander Plyusnin - Responsible for the molecular analyses and interpretation. All co-authors reviewed the manuscript.
References

1. Jameson LJ, Logue CH, Atkinson B, Baker N, Galbraith SE, Carroll MW, et al. The continued emergence of hantaviruses: isolation of a Seoul virus implicated in human disease, United Kingdom, October 2012. Euro Surveill. 2013;18(1): pii $=20344$. Available from: http://www.eurosurveillance.org/ViewArticle. aspx?Articleld $=20344$

2. Jameson LJ, Taori SK, Atkinson B, Levick P, Featherstone CA, van der Burgt $G$, et al. Pet rats as a source of hantavirus in England and Wales, 2013. Euro Surveill. 2013;18(9):pii=20415. Available from: http://www.eurosurveillance.org/ViewArticle. aspx?Articleld $=20415$

3. Jonsson CB, Figueiredo LT, Vapalahti O. A global perspective on hantavirus ecology, epidemiology, and disease. Clin Microbiol Rev. 2010;23(2):412-41

http://dx.doi.org/10.1128/CMR.00062-09

PMid:20375360 PMCid:PMC2863364

4. Brummer-Korvenkontio $M$, Vaheri A, Hovi T, von Bonsdorff $\mathrm{CH}$, Vuorimies J, Manni T, et al. Nephropathia epidemica: detection of antigen in bank voles and serologic diagnosis of human infection. J Infect Dis. 1980;141(2):131-4. http://dx.doi.org/10.1093/infdis/141.2.131 PMid:6102587

5. Vapalahti O, Mustonen J, Lundkvist A, Henttonen H, Plyusnin A, Vaheri A. Hantavirus infections in Europe. Lancet Infect Dis. 2003;3(10):653-61.

http://dx.doi.org/10.1016/S1473-3099(03)00774-6

6. Vaheri A, Henttonen H, Voutilainen L, Mustonen J, Sironen T, Vapalahti 0. Hantavirus infections in Europe and their impact on public health. Rev Med Virol. 2013;23(1):35-49. http://dx.doi.org/10.1002/rmv.1722 PMid:22761056

7. Yanagihara R. Hantavirus infection in the United States. epizootiology and epidemiology. Rev Infect Dis. 1990;12(3): 449-57.

http://dx.doi.org/10.1093/clinids/12.3.449

PMid:1972804

8. Heyman P, Plyusnina A, Berny P, Cochez C, Artois M, Zizi M, et al. Seoul hantavirus in Europe: first demonstration of the virus genome in wild Rattus norvegicus captured in France. Eur J Clin Microbiol Infect Dis. 2004;23(9): 711-7. http://dx.doi.org/10.1007/s10096-004-1196-3 PMid:15322934

9. Heyman P, Baert K, Plyusnina A, Cochez C, Lundkvist A, Esbroeck MV, et al. Serological and genetic evidence for the presence of Seoul hantavirus in Rattus norvegicus in Flanders, Belgium. Scand J Infect Dis. 2009;41(1):51-6. http://dx.doi.org/10.1080/00365540802459994 PMid:18821445

10. Plyusnina A, Heyman P, Baert K, Stuyck J, Cochez C, Plyusnin A. Genetic characterization of Seoul hantavirus originated from Norway rats (Rattus norwegicus) captured in Belgium. J Med Virol. 2012;84(8): 1298-303.

http://dx.doi.org/10.1002/jmv.23321 PMid:22711359

11. Mace G, Feyeux C, Mollard N, Audia S, Rebibou JM, Spagnolo G, et al. Severe Seoul hantavirus infection in a pregnant woman, France, October 2012. Euro Surveill. 2013;18(17): pii=20464. Available from: http://www.eurosurveillance.org/ViewArticle. aspx?Articleld $=20464$

12. Lundkvist Å, Hukic M, Hörling J, Gilljam M, Nichol S, Niklasson $B$. Puumala and Dobrava viruses cause hemorrhagic fever with renal syndrome in Bosnia-Herzegovina: evidence of highly cross-neutralizing antibody responses in early patient sera. I Med Virol. 1997;53(1):51-9. http://dx.doi.org/10.1002/ (SICI)1096-9071(199709)53:1〈51::AID-JMV9〉3.0.CO;2-P

13. Felsenstein J. PHYLIP (Phylogeny Inference Package) version 3.5C. Distributed by the author. Seattle: Department of Genetics, University of Washington; 1993. PMCid:PMC202139

14. Kallio ER, Klingstrom J, Gustafsson E, Manni T, Vaheri A, Henttonen $\mathrm{H}$, et al. Prolonged survival of Puumala hantavirus outside the host: evidence for indirect transmission via the environment. J Gen Virol. 2006;87(Pt 8):2127-34. http://dx.doi.org/10.1099/vir.0.81643-0 PMid:16847107

15. Hardestam J, Karlsson M, Falk KI, Olsson G, Klingstrom J, Lundkvist $\AA$. Puumala hantavirus excretion kinetics in bank voles (Myodes glareolus). Emerg Infect Dis. 2008;14(8):120915. http://dx.doi.org/10.3201/eid1408.080221 PMid:18680643 PMCid:PMC2600398 